\title{
Claves ocultas del pensamiento de Palma
}

\author{
Por Roland Forgues
}


Doctor Honoris Causa de la URP. Miembro Correspondiente del Instituto Ricardo Palma. Ha recibido homenajes en la Universidad de Puerto Montt (Chile), en el Instituto de Westminster, en Estados Unidos y en el Centro de Estudios la Mujer en la Historia de América Latina, de Lima. 
Hablar de Ricardo Palma es como hablar de un mito que contribuyó a forjar y propalar las acerbas polémicas que se armaron en su tiempo acerca de su personalidad, entre conservadores y progresistas, liberales y revolucionarios, moderados y radicales. Siempre tengo en la memoria la violenta diatriba de Manuel González Prada contra el patriarca de las letras peruanas, como se lo consideraba entonces, en su famoso discurso del Politeama de 1888: "iLos viejos a la tumba; los jóvenes a la obra!" Mientras, al revés, Víctor Raúl Haya de la Torre, fundador del APRA, y José Carlos Mariátegui, fundador del Partido Socialista Peruano, eminentes figuras de la "nueva generación" como González Prada, trataron de interpretar el pensamiento de Palma en un marco más favorable procurando rescatarlo de la tentativa de recuperación conservadora capitaneada por José de La Riva Agüero, otro de los notables intelectuales de la época.

Las claves ocultas del pensamiento de Ricardo Palma hay que buscarlas, creo, menos en su compromiso político y su actitud vital que en sus propios textos cuya escritura se ve determinada por motivaciones inconscientes que se manifiestan, especialmente en la percepción y tratamiento del tiempo.

Como ya señalé de paso en una conferencia ${ }^{1}$ del 2007, sin explayarme en el asunto que quisiera explicitar y profundizar

I "Revisitando a Palma en el siglo XXI. Disidencia y utopía". Aula Palma VI, Instituto Ricardo Palma, Lima, 2007, p. 247-268. 
ahora en esta nueva conferencia, el autor de Las tradiciones establece en su obra un vínculo secreto entre Pasado, Presente y Futuro como permanencia y proceso de cambio, como intemporalidad y cronología, como mito e historia, teoría y acción; en una palabra como realidad y utopía. No se trata, ni mucho menos, de una superposición de los tiempos, sino de una construcción que no destruye las fronteras temporales sino que las niega en un proceso de superación permanente.

A través de esta percepción y tratamiento del tiempo en sus textos, Ricardo Palma está reanudando, de algún modo, inconscientemente, una de sus pasiones originales: la acción política y social.

\section{La forma nueva de la tradición}

La elección de la forma de la Tradición es un elemento importante, en la voluntad de Ricardo Palma de construir un género literario nuevo que participe al mismo tiempo de la historia y de la ficción o mejor dicho un género literario que funde verdad y mentira.

En "Parrafadas de crítica" comparando la tradición con la historia escribe Palma:

En el fondo, la Tradición no es más que una de las formas que puede revestir la Historia, pero sin los escollos de ésta. Cumple a la Historia narrar los sucesos secamente, sin recurrir a las galas de la fantasía, y apreciarlos, desde el punto de vista filosófico social, con la imparcialidad de juicio y elevación de propósitos que tanto realza a los historiadores modernos Macaulay, Thierry y Modesto de Lafuente. La Historia que desfigura, que omite o que aprecia solo los hechos que convienen o como convienen; la Historia que 
se ajusta al espíritu de escuela o de bandería, no merece el nombre de tal. ${ }^{2}$

El escritor precisa su pensamiento dando los contornos de la llamada "Tradición" a la que diferencia claramente de la Historia. Ambas se sostienen en pilares distintos, aunque complementarios: la objetividad y la razón analítica para la Historia, la subjetividad y la fantasía creadora para la Tradición:

Menos estrechos y peligrosos son los límites de la Tradición. A ella, sobre una pequeña base de verdad, le es lícito edificar castillos. El tradicionista tiene que ser poeta y soñador. El historiador es un hombre del raciocinio y de las prosaicas realidades. La Tradición es la fina tela que dio vida a las bellísimas mentiras de la novela histórica, cultivada por Walter Scott en Inglaterra, por Alejandro Dumas en Francia y por Fernández y González en España. ${ }^{3}$

En el mismo texto Ricardo Palma define la forma de la Tradición que es lo que le dará efectivamente su estatuto no verdaderamente de género equiparable con los otros géneros literarios conocidos sino de breves narraciones que el propio autor califica según las circunstancias de historia, biografía, crónica, artículo de costumbres, narración histórica, leyenda, fábula, historieta, romance, cuento, entre otras. Aunque cierto es que Ricardo Palma está convencido de que estos textos, a pesar de su variedad conforman un mismo género. Así en los apuntes biográficos que en 1890 le envía a Francisco de Sosa anota: "En literatura he sido una especie de cajón de sastre. Cultivé todos los géneros, hasta que acerté con un filón riquísimo para mí -el de las tradiciones-. El género cayó en gracia y me ha dado cierta popularidad". 4

2 Ricardo Palma. Tradiciones peruanas completas. Ed. Aguilar, Madrid 1968, p.1474-1475.

3 Op. cit p.1475.

4 Tradiciones peruanas completas, p.1357. 
No carece de interés para apreciar la novedad de la escritura palmista recordar cómo el escritor concibe el estilo de la llamada "Tradición", de la cual ha hecho su actividad creadora predilecta:

Estilo ligero, frase redondeada, sobriedad en las descripciones, rapidez en el relato, presentación de personajes y caracteres en un rasgo de pluma, diálogo sencillo a la par que animado, novela en miniatura, novela homeopática, por decirlo así, eso es lo que, en mi concepto ha de ser la Tradición. ${ }^{5}$

Como se observará tenemos en estas palabras motivadas por un comentario a las Tradiciones cusqueñas de Clorinda Matto de Turner, todos los ingredientes de la creación que serán recogidos y formalizados más tarde por Mario Vargas Llosa con su teoría sobre "la verdad de las mentiras", empezando por las palabras "novela en miniatura" y sobre todo "novela homeopática" que diferencia claramente, como en el caso de la medicina alopática y homeopática, la "Tradición” de la "novela" por su principio activo, esto es: la forma que funciona de manera distinta en ambas narraciones. Mientras en la novela la ficción desordena y reordena la realidad, en la Tradición es la realidad la que desordena y reordena la ficción mediante la incorporación de aquello que Palma llama el "parrafillo histórico".

Pero el proceso de creación es idéntico. La verdad se convierte en mentira y la mentira restituye la verdad. Lo subraya de modo inequívoco la exclamación de Palma:

iCuantas noticias y fechas históricas, salvadas para siempre del olvido, va a encontrar el lector en las preciosas páginas que entre

5 Idem.

6 Remito al respecto al primer capítulo "La verdad de las mentiras. Para una teoría sobre la producción recepción de la obra de arte" de mi libro Mario Vargas Llosa, ética y creación. Editorial Ricardo Palma, Lima 2009, p.27-43. 
las manos tiene! La autora sabe hacernos vivir en el pasado, en un pasado embellecido por no sé qué mágico y misterioso hechizo que adormece en el ánimo los dolores del presente y cicatriza las heridas de nuestros recientes e inmerecidos infortunios, haciéndonos alentar la esperanza de mejores días y la fe en que llegarán tiempos de reparación y desagravio para la honra de nuestra abatida nacionalidad. ${ }^{7}$

Estas palabras que amalgaman Historia y Ficción son ciertamente la mejor de las definiciones que se puede dar de la Tradición, según Palma.

Al mostrar precisamente que la Tradición no es más que "una de las formas que puede revestir la Historia" considerada como ciencia de lo real, el escritor, inconsciente e implícitamente, está dando forma al proceso de conocimiento de lo real que surge de esa extraña relación entre la verdad que sirve de base a la Tradición y la mentira que le da su estatuto de Tradición.

Esta reflexión sobre la Tradición, definida por su indisociable vínculo entre verdad y mentira, historia y ficción, surge de algún modo de aquello que Mario Vargas Llosa llama la insatisfacción del escritor frente a la vida que le ha tocado vivir y las mil vidas que hubiera querido vivir, de una tentativa de reunir realidad y utopía.

La frustración de Palma en el campo político es ciertamente un elemento decisivo en su dedicación a la literatura. En una carta del 10 de junio de 1878, dirigida al Dr. Manuel Tamayo y Baus de la Real Academia Española que acaba de incorporarlo en su seno como miembro correspondiente el nuevo académico confía: "Serví a mi patria como Diputado, primero, y después,

7 "Parrafadas críticas", Op.cit, p 1475. 
como Senador, en cuatro legislaturas: me convencí de que perdí lastimosamente mi tiempo y me retiré a cuarteles de invierno, es decir, busqué refugio y solaz en la historia y la literatura".

Busqué refugio y solaz en la historia y la literatura, dice significativamente Ricardo Palma reuniendo como elementos constitutivos de su identidad los dos componentes esenciales e indisociables de la tradición: Historia y Ficción.

Con dichas palabras, Palma en cierto modo, ilustra a la maravilla aquello que Mario Vargas Llosa escribirá más tarde en su ensayo sobre García Márquez: Historia de un deicidio:

El por qué escribe un novelista está visceralmente mezclado con el sobre qué escribe: los 'demonios' de su vida son los 'temas' de su obra. Los 'demonios' hechos personas, sueños, mitos, cuya presencia o cuya ausencia, cuya vida o cuya muerte lo enemistaron con la realidad, se grabaron con fuego en su memoria y atormentaron su espíritu, se convirtieron en los materiales de su empresa de reedificación de la realidad, y a los que tratará simultáneamente de recuperar y exorcizar, con las palabras y la fantasía, en el ejercicio de esa vocación que nació y se nutre de ellos, en esas ficciones en las que ellos, disfrazados o idénticos, omnipresentes o secretos, aparecen y reaparecen una y otra vez, convertidos en 'temas' ".?

Los “temas" de sus Tradiciones están asentados en la historia y en lo real; y esto Ricardo Palma lo reafirma permanentemente como en estas palabras dirigidas a Carlos Toribio Robinet en enero de 1878 donde responde a un ataque del diario El Estandarte Católico de Santiago de Chile: "Mis tradiciones más que mías, son de ese cronista que se llama el pueblo, auxiliándome, y no

8 Ricardo Palma. Tradiciones peruanas completas. p.1528.

9 García Marquez: Historia de un deicidio. Ed. Seix Barral, barcelona, 1971, p. 87. 
poco los datos y noticias que en pergaminos viejos encuentro consignados. Mía es sin duda, la tela que las viste; pero no el hecho fundamental. Yo no invento, copio. Soy un pintor que restaura y da colorido a cuadros del pasado". ${ }^{10}$

Estos "temas", digo, asentados en lo real son de algún modo inconscientemente una manera de "recuperar y exorcizar" con las palabras y la fantasía de la forma, como bien dice Vargas Llosa, las frustraciones de su vida política y de hombre público de las que se queja a menudo en su epistolario; son los materiales que le permiten reedificar la realidad.

Recordaré de paso los desagrados y sufrimientos que expresaba Palma en una carta de 1889 dirigida a Vicente Riva Palacio, aludiendo a los ataques lanzados contra él por Manuel González Prada y algunos jóvenes de la "nueva generación":

Nada escribo, pues ni salud ni tiempo para ello tengo. Además empiezo a hastiarme de las letras por razones largas para escritas. Me he convencido de que en mi tierra, ya que ellas no dan pan debían siquiera dar honra. Una turba de muchachos, roídos acaso por la envidia, me ha puesto de oro y azul, hace tres meses, por un articulito que publiqué refutando ciertas doctrinas no liberales sino liberticidas y disociadoras. Yo creía haberme conquistado en mi país títulos para el respecto y consideración personal de todos mis compatriotas. ${ }^{11}$

No puede haber confesión más explícita sobre los "demonios" personales que están atormentando a Ricardo Palma y nos permiten aclarar en sus textos algunas claves ocultas de su

10 Tradiciones peruanas completas, p.1526.

11 Cit. por Flor María Rodríguez-Arenas, "Cronología”. En: Tradiciones peruanas . Edición crítica de Julio Ortega y Flor María Rodríguez.Arenas. Col Archivos, UNESCO, Paris 1996, p.359 
pensamiento que se revelan especialmente en el tratamiento del tiempo.

\section{El tratamiento del tiempo}

El tratamiento del tiempo, en efecto, tal como aparece en las Tradiciones, donde fusionan tiempo histórico y tiempo mítico en aquello que se podría llamar el tiempo de la conciencia humana, es ciertamente el elemento primordial de las claves ocultas del pensamiento de Ricardo Palma. Desde este punto de vista, no me parece casual precisamente que buena parte de las tradiciones se sostengan en refranes que si bien parten de la realidad concreta la trascienden para convertirse en verdades intemporales y trascendentes, de igual modo que lo son algunas anécdotas que se convierten en refranes, como es el caso de "iPues, bonita soy yo la Castellanos!", "Carta canta", "Después de Dios, Quirós", "Mas malo que Calleja" para tan solo refrescarnos la memoria.

Ya desde «Lida», una de sus primeras tradiciones, Palma se pregunta sobre la indisociabilidad de las tres instancias temporales: pasado, presente y futuro:

Y nosotros, generación parásita, que sin haber vivido en la noche existimos en el día, nosotros, flores henchidas de perfume y vida; nosotros los que decimos tenemos patria, quizá, negamos un recuerdo al Cristo del ayer.

Nosotros para quienes el astro rey no se hunde en el Océano, creemos eterno el hoy y nuestra miope mirada no alcanza al nebuloso horizonte del mañana; porque el mañana es el no ser. ${ }^{12}$

12 Ricardo Palma. Tradiciones peruanas. Edición crítica de Julio Ortega y Flor María Rodríguez-Arenas. p. 321. 
En la conclusión donde dice elocuentemente «Y en verdad os afirmo, que el mañana necesitará un Cristo que lo regenere de las manchas del presente » Palma termina fundiendo estas tres instancias en una sola que instaura un tiempo sin principio ni final, o sea el tiempo del mito y de la utopía.

El tratamiento del tiempo en las Tradiciones es, en realidad, el verdadero revelador de los valores en que se sustenta el pensamiento del autor y sus aparentes "contradicciones". Digo aparentes, porque en realidad las tales "contradicciones" no son sino las manifestaciones más visibles -y perfectamente coherentes si se las ubica en el contexto de la época- de un hombre que está viviendo en un mundo en plena mutación política, económica, social y cultural, con un notable cambio de mentalidad y de ética.

Ricardo Palma fundamenta su pensamiento en el acercamiento entre dos tipos de valores que no se excluyen sino que se completan. Por un lado, valores universales permanentes: los valores espirituales positivos o negativos que fundan la especie humana como tal y permiten su permanencia en el tiempo, es decir: valores que superan el tiempo histórico, cronológico, para fundar el tiempo mítico. Y, por otro lado, valores contingentes que se inscriben en el marco de los procesos históricos colectivos de las sociedades y civilizaciones; son los valores organizativos de la estructura económica, política, social y cultural, esto es: los valores que constituyen en un lugar y en un tiempo dado la norma de la vida en común de todo grupo humano.

El elemento clave que permite la fusión de ambos tiempos es el anacronismo y la descontextualización de lo contado del presente al pasado, y su recontextualización en un futuro que encarna la utopía. 
Gracias a este procedimiento en «El cigarrero de Huacho » (1874), por ejemplo, que ilustra perfectamente lo que aquí estoy diciendo, subtitulado « Cuento tradicional sobre unos amores que tuvo el diablo », Palma logra fundir el pasado de la Comedia de don Pedro Calderón de la Barca con el romanticismo de Víctor Hugo proyectándose en los tiempos venideros con el incendio de la cigarrería que le da a la aventura de la joven rebelde la intemporalidad del mito: "Para los huachanos fue desde entonces artículo de fe que el diablo, y no un galán de carne y hueso, era el que había cargado con la muchacha desobediente y casquivana". ${ }^{13}$

El juicio final del tradicionista, quien se dirige directamente al lector para aclararle la situación, convierte dicho tiempo en tiempo de la conciencia humana, esto es: un tiempo que desmitifica los valores religiosos tradicionales que rigen el presente y afirma nuevos valores fundamentados en el amor y la libertad; valores estos que apuntan también a la liberación de la mujer, que es otra de las grandes preocupaciones manifestada por Ricardo Palma en sus Tradiciones ${ }^{14}$ :

Aunque nadie volvió a tener en Huacho noticia de Eduvigis ni de su amante, yo te diré lector, en confianza, que el incendio fue un suceso casual: no hubo tal azufre ni cuerpo quemado sino en la sencilla preocupación del pueblo; que don Dionisio no tenía de diablo más que lo que tiene todo mozo calavera que se encalabrina por un regular coramvobis; y que huyendo de las iras de doña Angustias, se dirigieron las amorosas tórtolas a Trujillo, donde una tía del galán les brindó generoso amparo. ${ }^{15}$

13 Op. cit, p.696

14 Remito al respecto a mi artículo: "Visiones y reivindicaciones de género en el Perú: Flora Tristán y Ricardo Palma” Aula Palma VII, 209, p.327-336.

15 Op.cit, p.696. 
Sabemos la importancia que Ricardo Palma le concede a la lengua y al estilo. Por ello, es lícito ver en el calificativo "generoso" que emplea para calificar el amparo que la tía del galán les brinda a los jóvenes enamorados fugitivos, un claro indicio de la mirada benevolente que el cronista echa sobre el acto de rebeldía y de fuga.

En dicha crónica se van reuniendo pasado y presente en el marco de un fluir permanente e intemporal de la historia vista siempre en una dimensión crítica con el apoyo del humor y de la ironía. Palma lo confirma con la siguiente exclamación « iQuizá la situación de Judas era idéntica a la que hogaño aflige a los pensionistas del Estado! ».

Breves llamadas de atención como este sobre la reunión de los tiempos son frecuentes en los textos de Palma. A primera vista sin importancia, cumplen la función capital de presentar la historia en su doble vertiente de diacronía y sincronía. Así, por ejemplo, en « Los caballeros de la capa », podemos leer:

Don Francisco Pizarro se adelantaba a su época, y parecía más bien hombre de nuestros tiempos, en que el enemigo no siempre se mata o aprisiona, sino que se le quita por entero o merma la ración de pan. Caídos y levantados, hartos y hambrientos, eso fue la colonia, y eso ha sido y es la república. ${ }^{16}$

"La honradez de una ánima bendita" (1628) concluye con la siguiente reflexión del tradicionista que incide en lo mismo:

Ahora bien, digo yo: ¿no convienen ustedes conmigo que en este condenado y descreído siglo XIX las benditas ánimas del Purgatorio se han vuelto muy pechugonas, tramposas y sin vergüenza? Para

16 Op.cit, p.54 
delicadeza, las ánimas benditas de ha tres siglos. Hemos visto a una de estas infelices en trajines de otro mundo a éste para pagar una miserable deuda de doscientos pesos. ¿Y hoy? Mucha gente se va al otro barrio con trampa por centenares de miles y en el camino se les borra de la memoria hasta el nombre del acreedor. ${ }^{17}$

En el mismo orden de ideas de fusión de las instancias temporales en "El alcalde de Paucartambo" (1614), el tradicionista lamenta que "lo que llaman civilización, luces y progreso del siglo" haya suprimido al diablo que se propone resucitar cuando vuelva a ser diputado a Congreso.

Y en "El tamborcito del pirata" Palma insiste en su crítica de la ausencia de ética que ha surgido de las nuevas doctrinas positivistas y liberales:

Entonces se creía. Para bien y para mal se buscaba, ante todo la protección del cielo. Hoy hemos eliminado a Dios, porque nuestra fatuidad nos hace pensar que nos bastamos y nos sobramos para todo, y que Dios no pasa de ser un símbolo convencional para embaucar bobos y hacer a los frailes caldo gordo.

iEs mucho cuento la ilustración de nuestro siglo, escéptico, materialista y volteriano! ${ }^{18}$

A nadie se le escapará que aquello que lamenta Palma en este y otros textos es la desaparición de los valores morales permanentes, o míticos, bajo la presión de los valores materiales contingentes de la realidad.

Aunque el « consabido parrafillo histórico » o sus equivalentes, con el cual el tradicionista acompaña siempre sus crónicas,

17 Op.cit, p.345

18 Op.cit, p.277 
puede aparecerle un tanto artificial al lector actual, esta obligación que se impone Palma de insertar su texto en el tiempo histórico a través de referencias a fuentes escritas $\mathrm{u}$ orales tiene como función primera, aunque el escritor no tenga realmente conciencia de ello, de asentar la realidad ficticia de sus Tradiciones como realidad única y verdadera, como afirmaba el ensayista francés Maurice Blanchot al hablar de la ficción literaria y así legitimar su utopía a partir de una escritura concebida, consciente o inconscientemente, como "verdad de las mentiras".

Recordaré de paso el límpido comentario que Palma incluye en su famosa tradición "El corregidor de Tinta" (1780) que confirma con meridiana claridad lo que acabo de afirmar:

Aquí deberíamos dar por terminada la tradición; pero el plan de nuestra obra exige que consagremos algunas líneas por vía de epílogo al virrey en cuya época de mando aconteció este suceso. ${ }^{19}$

Es interesante observar que las referencias históricas siempre vienen introducidas en la tradición a través de una implicación directa del tradicionista en primera persona. De la misma manera que la primera persona es también la que sostiene los juicios emitidos sobre lo narrado. Vale decir que la voz presente de la narración fusiona con la voz pasada de lo narrado, según revelan a su vez los constantes llamados de atención al lector quien, de esta manera, se ve directamente implicado en lo narrado.

Para concluir, agregaré simplemente que si bien la obra de Palma se inserta en la historia del Perú de los siglos pasados, también constituye un elemento de comprensión de los tiempos

19 Op.cit, p.686. 
presentes y de reflexión sobre los tiempos venideros, en la medida en que, de algún modo, instaura como norma de vida el tiempo intemporal de la conciencia humana. 